\title{
Exploiting Music and Dance Notation to Improve Visualization of Data in BIM
}

\author{
Marcel Broekmaat, M.Sc. ${ }^{1}$ and Ioannis Brilakis, Ph.D. ${ }^{2}$ \\ ${ }^{1}$ Director of Product Management, Trimble Connect Collaboration Software, Trimble Inc. \\ ${ }^{2}$ Visiting Professor, Technical University of Munich; Laing O’Rourke Reader University of \\ Cambridge.
}

\begin{abstract}
Suboptimal information sharing is a key a factor that negatively impacts the construction sector's massive productivity gap when compared to other sectors of the economy. This is due to management difficulties, supply chain issues and rework. Building Information Modeling has been shown to improve dissemination of information but has not yet been exploited to its full potential. In this paper, we propose a new notation for visualizing project information in a BIM context. It is inspired by music and dance notation, and is designed to overcome current limitations that may cause the technology's limited use during the construction phase. A proof of concept was implemented and tested in an experiment with stakeholders. The use of the proposed BIM notations appeared to make access to and interpretation of available data more effective and resulted in more correct responses.
\end{abstract}

\section{INTRODUCTION}

Construction projects are frequently characterized by cost overruns, schedule delays and poor quality of work. The existence of these problems is reflected in poor productivity numbers for the industry (Teicholz 2013). Productivity, or productive time, is defined as the successful conversion of production factors (labor, material and equipment) into product (facilities or structures). Single Factor Productivity is typically used in construction and uses "labor" as the driving cost factor to determine the ratio against work in place or "earned value” (Weber \& Lippiatt 1983; van Beveren 2012). The equation that is used throughout this paper when discussing productivity of supervisors and engineers is:

Equation 1: $\quad$ Single Factor Productivity in Construction $=\frac{\text { output }}{\text { Input }}=\frac{\text { Installed Quantity }}{\text { Labour Hours }}$

Productivity problems are caused by inefficient use of time. Previous research contains evidence for the existence of a variety of issues related to inefficiencies in the industry. Horman \& Kenley (2005) found that $49.6 \%$ of activities performed on projects are wasteful and Picard's analysis (2004) establishes that average productive use of time ranges between $40 \%$ and $60 \%$. Josephson et. al. (2002) found that the average cost of rework was $4.4 \%$ of reviewed project value and that the time to correct this rework was $7.1 \%$ of the total work time. Rework was $26 \%$ design related and $25 \%$ due to management's misunderstanding of project data. Baloyi \& Bekker (2011) describe delays caused by design changes, slow decision making and poor information dissemination. Vrijhoef \& Koskela (2000) analyzed supply chains and discovered cost increases of 40\% to 250\% of the purchase price to remedy extra work due to incomplete information. Inaccurate and incomplete communication of project data appears to have a considerable impact on productivity. 


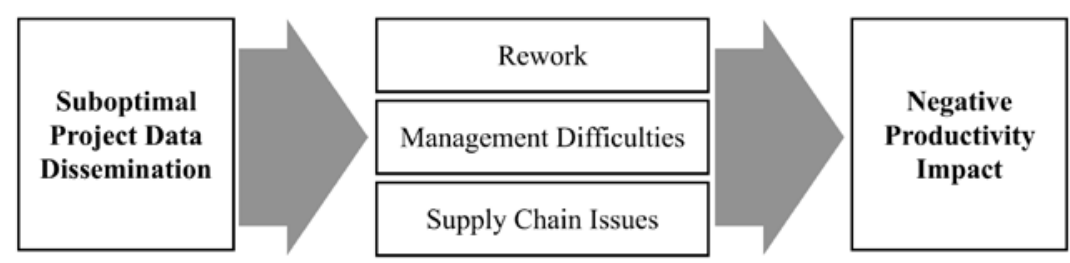

Figure 1 - Impact of Suboptimal Dissemination of Project Data

A cause of the information dissemination problem is that inputs are often not ready for immediate consumption. Disconnected documents, drawings and other files ("data") first have to be combined into a "mental model" (a visualization of the end result) to make them comprehensible and actionable, resulting in significant processing times during which workers and suppliers end up waiting for instructions. Furthermore, due to the variety of stakeholders involved, multiple interpretations exist. Because of the preference for individuals' own personal models, (Ragni \& Knauff 2013), decision makers tend to ignore interpretations of other stakeholders. The result is waste of management time, miscommunication, project execution problems and, consequently, lower productivity. Construction firms have adopted a variety of tools and methods in an attempt to improve data sharing on projects. Building Information Modeling (BIM), project and document management software, 4D simulations and visualization tools are in use throughout the industry. New methods such as lean production management and (advanced) work package management are being introduced with varying levels of success, but finding and using data inputs for a scope of work is a time-consuming activity that remains largely unsolved. BIM could provide context to limit the interpretation effort. However, BIM use currently focuses on coordination of design and engineering inputs. Data enclosed in BIM elements remains mostly unused during construction. 4D BIM visualizes construction planning data but requires significant amounts of non-productive time for linking of 3D geometry to tasks. Adopted tools are deployed to solve specific business problems but fail to address the issue of disconnected data.

\section{STATE OF RESEARCH}

Previous research proposes improvements in scheduling, work planning and use of BIM. Gantt Bar Charts, Critical Path Method (CPM) and Program Evaluation Review Technique (PERT) scheduling methods and software are commonly used for construction planning, but many projects are delayed upon completion. Effective time control is inhibited by design changes, project risk, complexity of works and non-performance of subcontractors. Potential improvements focus on collaboration or work readiness and not on scheduling techniques (Olawale \& Sun 2010). The Last Planner System (LPS) is an implementation of "lean thinking" in construction and aims to address the schedule reliability problem by moving the responsibility for planning to those who are responsible for performing the work (Ballard \& Tommelein 2016). The goal of "Takt Time Planning” is to synchronize production processes (Frandson \& Tommelein 2014). To improve productivity through implementation of LPS or Takt time planning, availability of task-specific information (readily consumable data in context) is key. The Construction Productivity Handbook (Construction Industry Institute 2014) defines “Advanced Work Packages”, with an emphasis on availability and status information. Modelling of work spaces and detection of time-space conflicts, as proposed by Akinci (2002) and developed by Kassem, Dawood and Chavada (2015) appears to be a more feasible solution for 4D BIM, but still involves additional work in a software tool, which is a barrier for adoption. Due to the extra work that is not owned by traditional project 
team members, adoption of 4D BIM remains relatively low. Gledson and Greenwood (2016) found that UK contractors mostly use 4D BIM to present the planned approach to their customers to win work.

Previous research describes how BIM can complement lean production practices. However, current BIM tools lack the ability to communicate planned work, required inputs, risk and constraints (other than space allocations) to workers onsite. Reviewed studies have not proposed or tested methods for including this information. 4D BIM simulations typically visualize "as planned" conditions and are not updated with current status. While researchers propose including more construction data, implementations are not described beyond concept and anticipated value. Therefore, work readiness status, as proposed in research describing Last Planner System and Takt time planning, is not available within the BIM context. As a consequence, what is currently presented through BIM is limited to simulations of the construction sequence and model elements that represent the end state of the project. Construction process information continues to reside in a variety of planning tools outside BIM.

The need to share detailed process information to accomplish a defined common goal is not unique to construction. In the tech industry, status information is often shared through schema techniques such as RACI (Rosser et al. 2014) and in tools such as Kanban and Scrum (Lei et al. 2017). In music and dance, a rich set of information is made available to members of the orchestra or dance ensemble through a notation system that places a well-defined set of symbols on a staff that represents time (Hutchinson Guest 1990; Wilke et al. 2005; McLachlan et al. 2010). The conductor reinforces the timeline by guiding the orchestra or ensemble through a pace (marked by the music's beat), which can be followed along on corresponding sheet music. Similar to music, construction has the concept of contributing parties and a "beat" in the form of planned weekly output, which sets the pace for a project. However, a notation system that can be referenced by stakeholders for status and pace-setting does not yet exist.

\section{PROPOSED SOLUTION}

Addressing the currently existing gap between BIM tools and desired support for decision making to improve productivity requires a solution that facilitates access to project data in a BIM context. Users of current solutions have to navigate 3D models and select individual elements in current BIM tools to access data. Results are presented as properties of selected elements. However, supervisors and engineers make decisions based on data that is related to multiple elements that are typically associated with a location or a task. Therefore, a new solution is needed to provide access to a summary of relevant data in a specific location or for a specific task. Requirements for the proposed solution are:

Requirement A: automated association of BIM elements with project data for locations and tasks.

Requirement B: automated location, project phase and role assessment to determine what data should be presented to supervisors and engineers.

Requirement C: a notation for BIM that summarizes and communicates data relevant for current locations and tasks.

The proposed solution combines the lean production concept of "make ready” work with BIM. Lean's "make ready" work requires that project teams ensure availability of all needed inputs for a unit of work before the planned start of the work. The focus of the research was on solution 
requirement $\mathrm{C}$ and resulted in a new BIM notation that is inspired by qualities of music and dance notation. Music and dance notations present "note" and "movement" symbols on a timeline that uses markers for "meter" (or "beat"), which allows musicians and dancers to read notations by following along with the beat in performed music. The approach of markers for main units on a timeline is adopted for the BIM notation. However, contrary to music and dance, the BIM notation uses a logarithmic time scale with days, weeks and months as construction's equivalent to music's beat because project teams work towards weekly, monthly and annual delivery milestones. A nonlinear time scale is chosen to enable status updates and forecasts beyond the current week and to provide input for longer term preparation work. The notation presents status information for contract documents, design, schedule, material deliveries and QA checklists: key aspects that were chosen after analysis of a completed project's management data. Aspects are placed on a horizontal "staff" similar to music notation and are assigned a dedicated "lane" similar to dance notation. Colored symbols for selected aspects indicate current and forecasted status and potential downstream impact of risk to allow for review of readiness when preparing for scheduled work in a location. The notations present a summary of relevant data associated with the collection of BIM elements in a location to eliminate the need to examine individual elements.
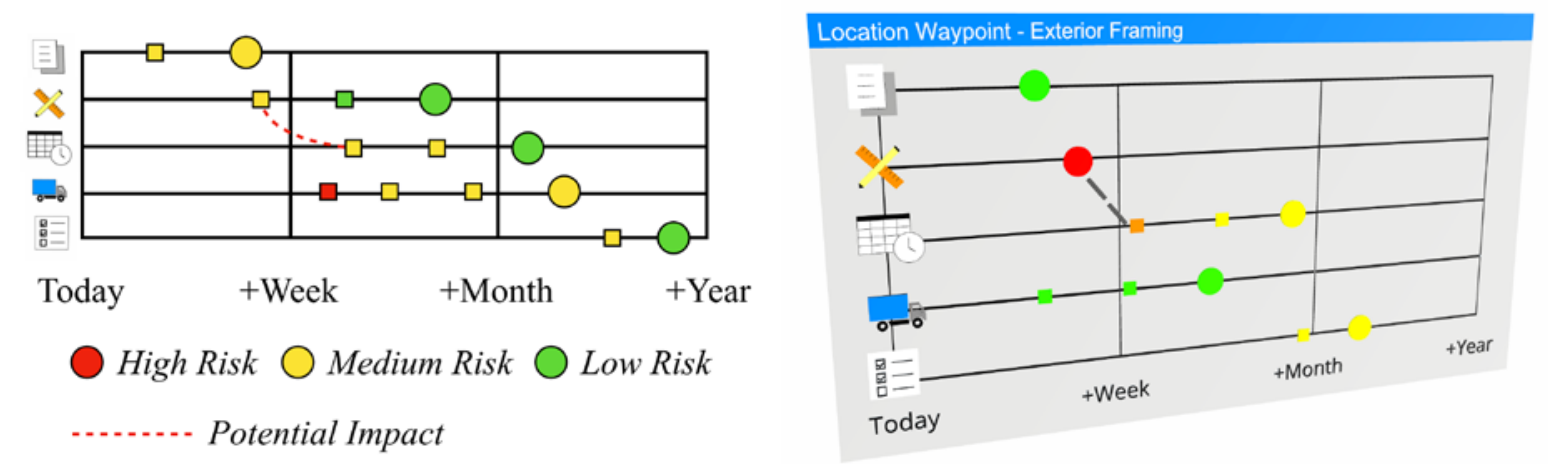

\section{Figure 2 - Proposed BIM notation, inspired by music and dance notation (left) and proof of concept implementation in BIM tool (right). The "staff” is used for 5 key aspects for successful completion of work: contract documents, design, schedule, material deliveries and QA checklists.}

\section{METHODOLOGY}

The value of the proposed solution for requirement $\mathrm{C}$ was tested in an experiment in which response time and accuracy for a series of ten questions was measured for individual participants. Designed questions were asked from subcontractor perspective and were related to status of ongoing or planned work. Answering the questions required use of available project data to determine whether issues existed that could impact the start of planned work. The questions were defined based on a set of real project data with input from one of its stakeholders. A proof of concept was implemented to test the value of the proposed solution by creating static 3D models in a BIM tool for a series of panels that contained the BIM notation. These panels were then placed in predefined BIM views. The BIM views were created to provide context for defined questions. Fifteen Project engineers, superintendents and project managers from 2 general contractors in the Denver, CO area were invited to participate in the experiment. Participants were assigned to an experiment group or a control group based on availability. Two sessions with the experiment group and two sessions with the control group were held. Participants in the control group were asked to 
answer the questions using the traditional set of inputs consisting of spreadsheets, documents, drawings and non-annotated BIM views. The experiment group also had access to the proof of concept notations in the BIM views. Questions, as well as the set of project data, were made available to the participants through an experiment website. The questions were embedded in the website as a questionnaire and data was automatically collected in a linked spreadsheet. For timing information, the participants were asked to specify the time when they started to work on a question in the form. Timing information was used to determine response times, average response time per participant and average response time per group. Responses were reviewed and scored for accuracy and completeness. The hypothesis was that input for decision making by supervisors and engineers could be improved with the introduction of the proposed BIM notations by making targeted, comprehensive data available in a BIM context. The assumption was that this would result in less time spent searching for data inputs and more accurate responses.

\section{RESULTS}

On average, participants with access to the proposed solution did better: 5 correct answers compared to 3 for participants who were asked to answer the same questions without the BIM notations. The average number of correctly answered questions in control group and experiment group was similar for company 1 and company 2. The results indicate that the hypothesis related to the presumed ability to answer questions more accurately with the support of the proposed solution could be confirmed within the context of this experiment.
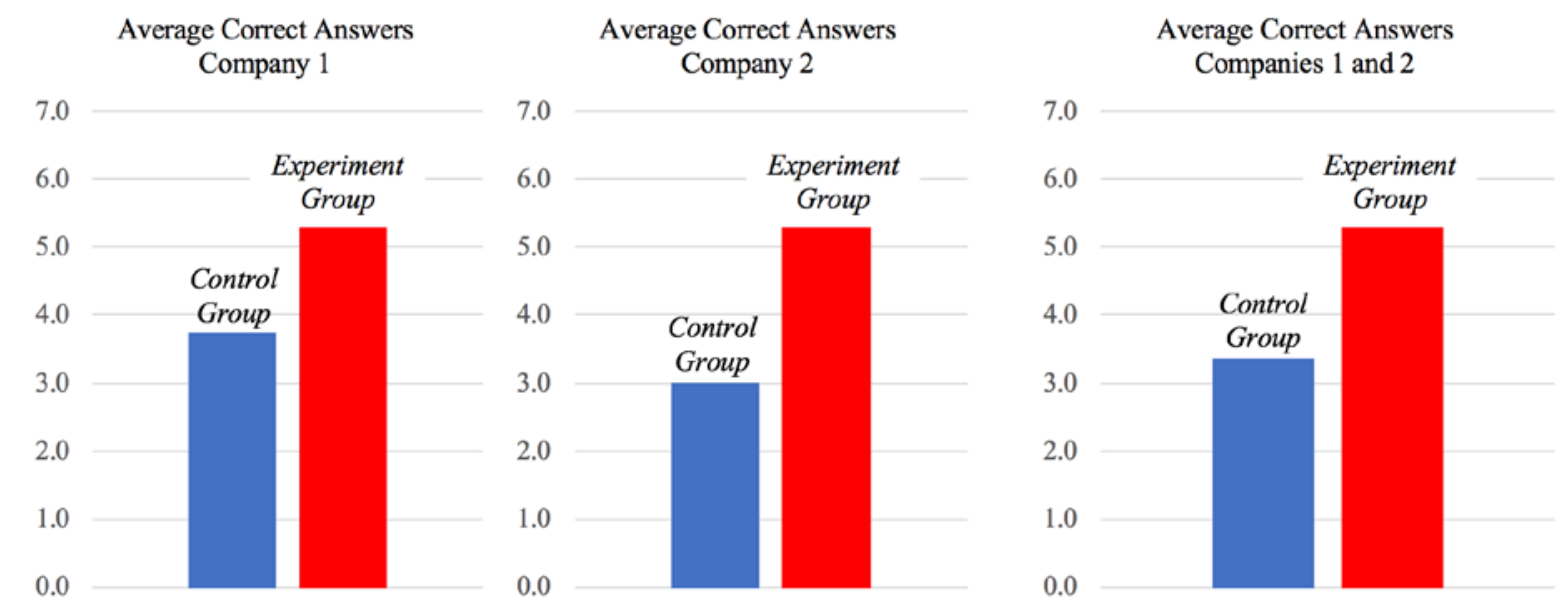

Graph 1 - Number of correct answers in control group and experiment group.

The hypothesis assumed that the time required to respond to questions would be shorter with access to proposed BIM notation tool. However, results showed that the opposite was true in the experiment. Participants in control groups needed less time per question than participants in experiment groups. The fact that more time was needed with the notations indicates a learning curve or usability issues. Seniority of participants played a role in the amount of time needed to complete responses. Senior project managers needed the least amount of time to respond in the control group but needed the most time in the experiment group. Project and field engineers, participants with less experience, needed more time in the control group and less in the experiment group. 


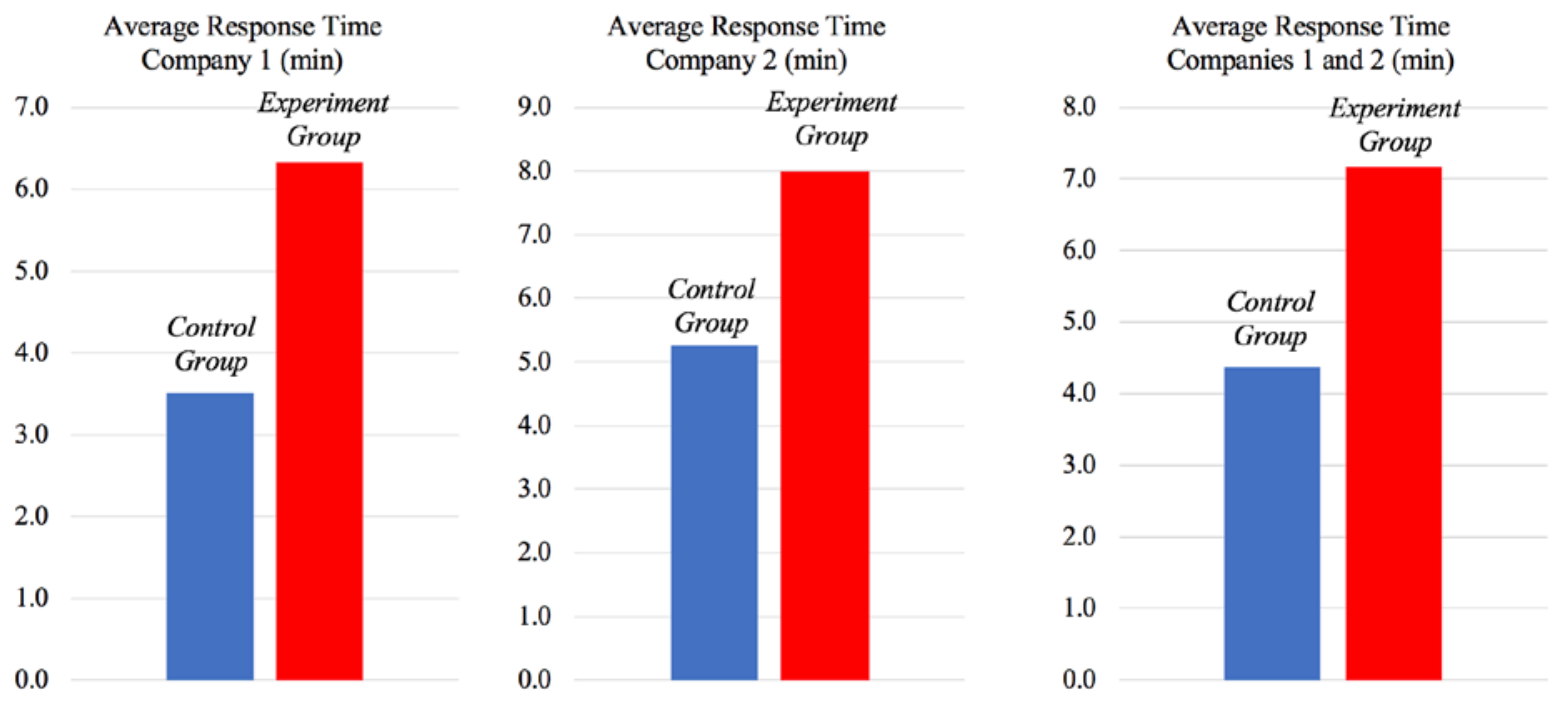

Graph 2 - Average response time in control group and experiment group.

Seniority is therefore seems to be a key factor in the ability to make decisions based on provided data. Review of the different results between the groups with and without access to the BIM notations resulted in a finding that less experienced personnel (with role descriptions project engineer, office engineer and field engineer) benefited more from available BIM notations than experienced participants. This notion of seniority having an impact on the utility of the BIM notations was analyzed further by assigning each of the participants a "seniority score", ranging from 1 to 3, with a score of 1 representing the least experienced.
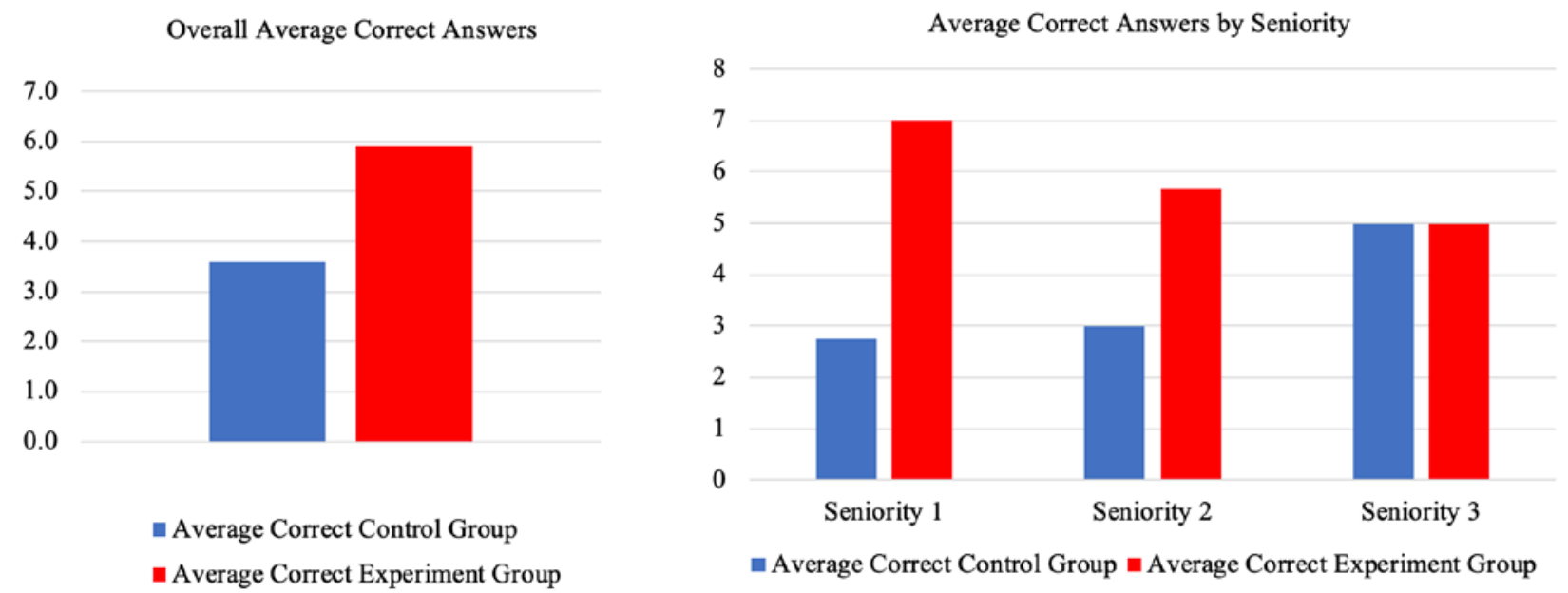

Graph 3 - Average number of correct answers by seniority.

The graph on the left shows a comparison between correct answers by all participants in control and experiment groups, the graph on the right shows how the difference in number of correct answers is larger for participants with lower seniority.

\section{CONCLUSIONS}

The number of correct answers increased for the experiment group. Proposed BIM notations may therefore have the potential to address the problem of multiple interpretations of distributed sets 
of data. As reported by Ragni (2013), individual interpretation of data sets leads to multiple mental models and conflicts between stakeholders due to a preference for their own interpretation or mental model. By bringing all relevant data for an element or a location together, a "systems engineering view" (Piaszczyk 2011) for construction could be created as a potential Lean support tool (Sacks et al. 2010). If the usability barrier for senior personnel of proposed solution can be eliminated with suggested improvements, the use of spatially organized information for "make ready" work may be help address current limited adoption of BIM by field personnel (Bryde et al. 2013; Lather 2016; Eadie et al. 2013).

Experiment results indicate that use of BIM technology with proposed solution was more beneficial for participants with fewer years of experience in the industry. However, these participants may have had more experience with the use of 3D models for design coordination purposes in their jobs. The results may also imply that it is difficult for supervisors and engineers who lack experience with BIM to access and consume data through the context of a 3D model.

A significant share of experienced supervisors in the construction industry will retire in the next decade. Results from this research show that experience was a key factor in participants' ability to make decisions based on disconnected data inputs. Experienced supervisors have skills to recognize and utilize important data in large sets, a skill that less senior personnel do not yet possess. Empowering the next generation of supervisors and engineers with better, more comprehensive inputs is therefore becoming urgent. Use of data in context through BIM notations appeared to have the most positive impact on least senior participants in the experiment and has the potential to enable younger people to manage jobs with less experience.

Further experiments and data collection with larger and more diverse groups will be needed to improve the reliability of experiment results. Calculated confidence intervals show overlaps in obtained experiment results, in particular in the analysis of seniority impact. More testing between groups with differing seniority will have to provide better evidence of the difference in benefit between less and more senior participants. Suggested improvements should be included in continued research, as well as support for requirements A (automated association of data) and B (automated assessment of location, role and project phase).

\section{REFERENCES}

Akinci, B., Fischer, M. \& Kunz, J., 2002. Automated Generation of Work Spaces Required by Construction Activities. Journal of Construction Engineering and Management, 128(4), pp.306-315.

Ballard, G. \& Tommelein, I., 2016. Current Process Benchmark for the Last Planner ® System. Lean Construction Journal, 89, pp.57-89.

Baloyi, L. \& Bekker, M., 2011. Causes of construction cost and time overruns : The 2010 FIFA World Cup stadia in South Africa. Acta Structilia, 18(1), pp.51-67.

van Beveren, I., 2012. Total factor productivity estimation: A practical review. Journal of Economic Surveys, 26(1), pp.98-128.

Bryde, D., Broquetas, M. \& Volm, J.M., 2013. The project benefits of building information modelling (BIM). International Journal of Project Management, 31(7), pp.971-980.

Construction Industry Institute, 2014. The Construction Productivity Handbook, Austin, Texas. 
Eadie, R. et al., 2013. BIM implementation throughout the UK construction project lifecycle: An analysis. Automation in Construction, 36, pp.145-151.

Frandson, A. \& Tommelein, I.D., 2014. Development of a takt-time plan: a case study. In Construction Research Congress 2014. pp. 1646-1655.

Horman, M.J. \& Kenley, R., 2005. Quantifying Levels of Wasted Time in Construction with MetaAnalysis. Journal of Construction Engineering and Management, 131(January), pp.52-61.

Hutchinson Guest, A., 1990. Dance Notation. Perspecta, 26, pp.203-214.

Josephson, P.-E., Larsson, B. \& Li, H., 2002. Illustrative Benchmarking Rework and Rework Costs in Swedish Construction Industry. Journal of Management in Engineering, 18(2), pp.76-83.

Lather, J.I., 2016. An Ontology for Interactive Workspaces and Their Use Cases Within Collaborative Design and Construction Practices. The Pennsylvania State University.

Lei, H. et al., 2017. A statistical analysis of the effects of Scrum and Kanban on software development projects. Robotics and Computer-Integrated Manufacturing, 43, pp.59-67.

McLachlan, N.M. et al., 2010. Using spatial manipulation to examine interactions between visual and auditory encoding of pitch and time. Frontiers in Psychology, 1(DEC).

Olawale, Y.A. \& Sun, M., 2010. Cost and time control of construction projects: Inhibiting factors and mitigating measures in practice. Construction Management and Economics, (28), pp.509-526.

Piaszczyk, C., 2011. Model Based Systems Engineering with Department of Defense Architectural Framework. Systems Engineering, 14(3), pp.305-326.

Picard, H.E., 2004. Driving Down Construction Project Labor Cost. Construction Management Association of America, pp.1-10.

Ragni, M. \& Knauff, M., 2013. A theory and a computational model of spatial reasoning with preferred mental models. Psychological review, 120(3), pp.561-88.

Rosser, L. et al., 2014. Systems Engineering for Software Intensive Projects Using Agile Methods, Garland, TX.

Sacks, R., Radosavljevic, M. \& Barak, R., 2010. Requirements for building information modeling based lean production management systems for construction. Automation in Construction, 19(5), pp.641-655.

Teicholz, P.M., 2013. Labor-productivity declines in the construction industry: causes and remedies (a second look). AECbytes, 1(67).

Vrijhoef, R. \& Koskela, L., 2000. The four roles of supply chain management in construction. European Journal of Purchasing \& Supply Management, 6(3-4), pp.169-178.

Weber, S.F. \& Lippiatt, B.C., 1983. Productivity Measurement for the Construction Industry, Washington, DC.

Wilke, L. et al., 2005. From dance notation to human animation: The LabanDancer project. Computer Animation and Virtual Worlds, 16(3-4), pp.201-211. 